\title{
ALTERIDADE, O OUTRO E A APRESENTAÇÃO DA NOÇÃO DE SUBJETIVIDADE EM EMMANUEL LEVINAS
}

\author{
R. R. S. MENDONÇA ${ }^{1,}$, F. S. CARDOSO ${ }^{2}$ \\ ${ }^{1}$ Universidade Federal de Pernambuco, ${ }^{2}$ Universidade de Pernambuco \\ cardosodh8@gmail.com ${ }^{2}$ \\ Submetido 07/02/2017 - Aceito 13/06/2018 \\ DOI: $10.15628 /$ holos.2018.5618
}

\section{RESUMO}

O presente trabalho problematiza o pensamento do filósofo lituano Emmanuel Levinas, procurando entender o conceito apresentado como o Outro a partir das noções de alteridade e subjetividade. Discute-se os argumentos do autor como intersecções a pensar a ideia de humano, e, também, sobre como a ideia de alteridade está relacionada ao reconhecimento do Outro que Levinas nos apresenta. O trajeto metodológico, de caráter bibliográfico-exploratório, perfaz o aprofundamento e a apresentação de reflexões acerca do humano enquanto ente responsável, importantes à construção da noção de subjetividade levinasiana aqui apresentada.

PALAVRAS-CHAVE: Levinas, alteridade, Outro, subjetividade.

\section{ALTERATIVITY, THE OTHER AND THE PRESENTATION OF THE CONCEPT OF THE SUBJECT BY EMMANUEL LEVINAS}

\begin{abstract}
The present work problematizes the thought of the Lithuanian philosopher Emmanuel Levinas, trying to understand the concept presented as the Other from the notions of otherness and subjectivity. The arguments of the author are discussed as intersections to think the idea of human, and about how the idea of otherness is related to the recognition of the Other that
\end{abstract}

Levinas presents to us. The methodological path, of a bibliographic-exploratory character, makes the deepening and presentation of reflections about the human as responsible entity, important to the construction of the notion of Levinasian subjectivity presented here.

KEYWORDS: Levinas, alterativity, Other, subjectivity. 


\section{APRESENTAÇÃO}

"Compreender o instrumento não consiste em vê-lo, mas em saber manejá-lo; compreender o ser é existir. Tudo isto está a indicar, ao que parece, uma ruptura com a estrutura teorética do pensamento ocidental."

(Emmanuel Levinas)

As concepções acerca do Outro apresentadas por Emmanuel Levinas, fundadas na ideia de alteridade, nos ajudam a compreender como o pensamento da sociedade ocidental construiu - e ainda constrói e reforça - dicotomias e padrões que culminam em discriminações. A ideia de diversidade e de diferença são ideias que constituem a concepção do Outro, do Outro que é diferente, diverso, que é diferente do destoante do imaginário ocidental-hegemônico. Quando se fala no diferente que destoante do imaginário ocidental-hegemônico, se faz referência à perspectiva estruturalista do sujeito, o ser humano que foi moldado e relacionado aos padrões arquetípicos impostos pelo Ocidente.

Estuda-se os binarismos/dicotomias e padrões que são estabelecidos e reforçados pelo ocidente para que, nesta pesquisa, relacione-se e leia-se tais normas, com base nas ideias advindas do filósofo Levinas, buscando alcançar alguns argumentos que podem contribuir com os estudos no campo dos direitos humanos e da diversidade humana.

Assim, propomo-nos a refletir sobre algumas questões: Quais as concepções sobre o humano, alteridade e reconhecimento no pensamento de Emmanuel Levinas? Os argumentos construídos a partir da ideia do Outro, em Levinas, podem apresentar sentidos à ideia de subjetividade na obra do autor? Por outro lado, entendemos que a reflexão sobre essa questão, pode-nos apontar alguns trajetos à noção de subjetividade no pensamento do autor. Hipoteticamente, pensamos que tais reflexões poderão nos ajudar na apresentação de ideias que quebram com o estruturalismo ocidental, que foi/é reforçado enquanto via à negação da condição humana de cada sujeito.

Nosso objetivo geral se orienta em: Compreender as concepções sobre o humano, alteridade e reconhecimento no pensamento de Emmanuel Levinas. Assim, para alcançar nosso objetivo, traçamos alguns objetivos específicos que são: i) compreender sobre o humano no pensamento de Emmanuel Levinas; ii) refletir as ideias de alteridade e reconhecimento em Emmanuel Levinas; e, iii) discutir o Outro no pensamento de Emmanuel Levinas. 
Nossa pesquisa se faz a partir do método hipotético-dedutivo, onde analisaremos a problemática, eliminando tudo o que for considerado como falso. Além desse método, temos também o dialético (GIL, 2009), onde buscaremos uma verdade por meio de oposição e conciliação de contradições. Fez-se uso, ainda, de pesquisa bibliográfica-exploratória, pois utilizou-se de materiais já elaborados, aprofundando-os.

É na perspectiva de contribuir com a apresentação de novas reflexões aos fundamentos dos direitos humanos que se idealiza este estudo, no qual as ideias de Mesmo e Sombra, trabalhadas por Levinas, contribuem para entendermos a concepção do Outro. Afinal, para Levinas, o Outro vai além de tudo o que já foi dito e estudado sobre o humano, um Outro pautado na ideia de alteridade necessita ser pensado. Em suma, os objetivos traçados no presente estudo se apresentam enquanto trajeto a uma releitura marcada pelo desvelamento de outros sentidos e significados sobre o pensamento levinasiano na contemporaneidade.

\section{SOBRE O HUMANO, ALTERIDADE E RECONHECIMENTO NO PENSAMENTO DE EMMANUEL LEVINAS}

A fundamentação teórica do presente artigo, dedicar-se-á ao estudo do filósofo Emmanuel Levinas, especialmente no que diz respeito às suas concepções sobre o humano. Serão também apresentadas discussões acerca da ideia de sujeito, e, finalmente, sobre os argumentos que perfazem as ideias de alteridade, Mesmo, Sombra, Outro, e suas possíveis (re)configurações a partir da reflexão sobre subjetividade no pensamento do autor.

Assim, as reflexões construídas no presente estudo direcionam-se, especialmente, às concepções teóricas sobre os conceitos de alteridade, Mesmo, Sombra, Outro, e suas possíveis (re)configurações a partir da reflexão sobre subjetividade no pensamento de Emmanuel Levinas.

\subsection{Sobre o Humano no Pensamento de Emmanuel Levinas}

Nascido em uma família judaica, na Lituânia, Levinas acredita que o ponto de partida para se estudar a filosofia é a ética, e não a ontologia. E que é a partir do reconhecimento do Outro, pautado na ideia de alteridade, que é possível respeitar e aceitar a diversidade humana, um humano que vai além de sua essência. 
Levinas aponta uma humanização do homem como estando ligada a ideia de alteridade, um Outro que é transcendente, que se preocupa. Um humano que não se esgota apenas no Eu, mas sim, se preocupando em explicar o sujeito em uma visão mais integral, entretanto, não se propõe a defini-lo, conceitua-lo ou padronizá-lo.

Carrara (2008, p. 22), nos mostra isso quando diz que:

\begin{abstract}
O sujeito deverá resistir a toda tentativa de uniformização que o submete a uma totalidade. A acusação mais frequente que Levinas faz à filosofia ocidental é a de ter apagado a diferença que se perde na unificação do todo [...] A concepção de subjetividade que Levinas propõe é uma ruptura com a totalidade e deverá ser pensada a partir do infinito que rompe com a totalidade.
\end{abstract}

Para Levinas, a ideia de humano está além de toda e qualquer categorização que já foi feita e dita até os dias de hoje, entende que as leituras sobre o humano são racionalistas e sempre repetitivas, uma vez que se busca categorizar o ser. Sobre os discursos e estudos realizados até hoje sobre o humano, Sayão (2009, p. 234) nos mostra que "são discursos conformados, cômodos, que alegam que todas as faces humanas já foram alcançadas e todos os sentidos possíveis à civilização apresentados". O autor alerta sobre um dado que Levinas busca se afastar: as definições e conceitos rígidos sobre o humano, que, na perspectiva levinasiana, é algo transcendente, nunca rígido.

Na descrição de Sayão (2009), vê-se uma clara relação com o pensamento de Levinas, uma vez que reafirma a não categorização do humano, e que este vai além de qualquer significação. Além do fato de que, por vezes, aceita-se estes conceitos sem maiores reflexões, como se não houvessem mudanças, e existisse uma constante inércia dos padrões estabelecidos na e pela sociedade ocidental.

Ainda sobre a concepção de humano a que Levinas se refere, Sayão (2012a, p. 244), ainda nos fala que Levinas busca uma sociedade que esteja baseada na "responsabilidade, cuidado e generosidade", e que, assim, tendo estes requisitos como primordiais, seria possível uma sociedade mais humana, fincado no sentido humano das relações estabelecidas.

Segundo Levinas, quando passamos a reconhecer o Outro, compreendendo suas necessidades, ajudando-o e exercitando a generosidade, temos uma visão mais ampla do que seja, de fato, e qual o verdadeiro significado da humanidade.

Nos dizeres de Melo (2003), que também discute as ideias de Levinas, não podemos nos prender a conceitos e/ou definições, uma vez que estas tolhem o ser humano, e não o concebem em sua completude. Ele ainda nos diz que: 
A transcendência do sujeito é a própria infinitude pessoal, a saída de si para o mundo misterioso do outro, que se revela somente pelos rastros da sua passagem. A transcendência é o fato mesmo da relação sem relação, do apelo ao outro, do "eis-me aqui". A transcendência é, ao mesmo tempo, significante e significação de uma comunicação aberta ao infinito pessoal (MELO, 2003, p. 71).

É possível observar que o humano de que trata Levinas é muito maior do que toda a categorização que pode ser feita a partir da racionalidade ocidental, e que seus pensamentos estão muito além de um cotidiano prático. Ele eleva o ser humano a uma subjetividade extrema, e é justamente essa transcendência um dos pontos de partida, que a nosso ver, devem ser considerados para que se possa tentar refletir o Outro.

A ideia de humano trazida por Levinas, é um humano que está baseado na ideia de preocupação com o Outro, um humano que se coloca no lugar do Outro, uma imagem construída a partir da alteridade. Sobre esse aspecto, Sayão (2009, p. 239) nos diz que: "Levinas fala do mais original do humano, exaltando horizontes delineados como sensibilidade em termos de vulnerabilidade e gozo, que resultam diante do Outro (alteridade) numa história de responsabilidade e substituição".

Para Lapa (2017, p. 84), a noção de alteridade também pode ser compreendida enquanto

[...] um elemento de relevância à fundamentação de direitos humanos, pois é a variável capaz de observar a diferença. Uma percepção da diferença que não serve a instrumentos de exclusão - mas antes à noção de que somente pela garantia da diferença, do direito a ter distintos direitos -, pode gerar uma fundamentação replicadora de ações mais efetivas de direitos humanos.

Uma vez reconhecidas as diferenças entre os sujeitos, e não mais se colocadas enquanto ferramenta para marginalizá-los, é possível lhes garantir direitos, reconhecendo-os enquanto sujeitos, para além da matriz ocidental clássica que representa o humano.

Levinas acredita em uma ideia de humano que está preocupado com a realização do Outro, um humano que não é egocêntrico. Para Levinas, a sociedade ocidental não se preocupa com o Outro, e, quando o faz, sempre há algum interesse. Assim, seria preciso que o humano fosse além de seus próprios interesses para que se busque a paz e a horizontalidade das relações humanas, pois os discursos que são feitos sobre generosidade e responsabilidade para com o Outro servem, muitas vezes, como discursos que geram "um estado de selvageria cujo argumento maior é a guerra" (SAYÃO, 2009, p. 236). 
Assim, com base no pensamento de Levinas, é preciso pensar uma nova humanidade, um [sempre] utópico humano, que se preocupa com o Outro, onde generosidade, respeito e ética são observados e praticados, um modelo de sociedade diferente de nossa sociedade ocidental (onde nossas próprias conquistas, interesses e realizações sempre se sobrepõem aos demais).

Corroborando com essa mesma perspectiva, Bonamigo (2016, p. 151) aduz que, sinteticamente, "a Subjetividade como identidade de si a si [...] é a lógica da preocupação por si. Por outro lado, a afirmação bíblica da prioridade do outro exige um "novo começo" para pensar a relação inter-subjetiva, a partir da lógica do cuidado do outro". O cuidado com o Outro exige entrega, uma pré-condição ao alcance da alteridade, ao passo que a subjetividade seria a preocupação com o próprio ser.

Partindo da ideia de que a ética é a filosofia primeira, Levinas, segundo Sidekum (2005, p. 03), nos apresenta um sempre renovado humanismo, no qual:

A perspectiva de seu pensamento abrange fundamentalmente a ética. A ética tem seu ponto de partida ao reconhecimento do outro, Levinas é um pensador que vai além das perspectivas da subjetividade, do psiquismo e da egologia da Modernidade, inserindo-se na compreensão do reconhecimento dos Direitos Humanos fundamentais ditados pela alteridade do outro que é fundamento e a dimensão teleológica da justiça.

Assim, é possível compreender que, para Levinas, a ética é de suma importância às relações humanas e a constituição dos sujeitos, pois é elemento orientador para que seja possível reconhecer o Outro em sua alteridade, e, assim, reconhecer, por exemplo, direitos humanos, que são fundamentais e inerentes a todo e qualquer sujeito, pois lhes garante existir em sua totalidade, sem que assim seja necessário corresponder as expectativas que fundam o imaginário hegemônico da sociedade ocidental.

Assim, conforme Sidekum (2005), o pensamento ocidental se trata de uma egologia, um egocentrismo. Por outro lado, a subjetividade humana se torna viável por meio da relação do eu com o Outro, relação que é, por si mesma, presente antes de sua própria origem, ou seja, antes mesmo que o meu eu exista já estava pré-estabelecido um elo onde o meu Eu é preocupado e responsável para com o Outro.

Melo (2003) nos mostra que toda a problemática está no fato de que a transcendência do sujeito não se estende até a gnosiologia, que é o estudo do conhecimento humano em torno da origem, e que, para Levinas, este seja o maior erro da sociedade ocidental. A transcendência humana se dá quando o ser humano vai além de sua própria existência, assim, "o sujeito se faz 
sujeito quando, no seio da imanência egoísta, rompe o próprio egoísmo e se abre à manifestação de outrem" (MELO, 2003, p. 74). Ainda em suas observações. Melo nos fala que: "Levinas elabora sua compreensão do ser como existente. Mas um existente sem existência. O homem concreto, o ser puro. Anterioridade e significação nunca passíveis de serem adjetivadas. Para ele a compreensão do ser é um modo de ser do existente" (2003, p. 76, grifo do autor).

Aqui, observamos, mais uma vez, que Levinas acredita na transcendência do humano, e de que ele foge a qualquer explicação ou definição que pode ser feita, de um ser humano que se preocupa com o Outro. Levinas busca uma sociedade mais humanitária, para que assim seja possível estabelecer uma sociedade onde um indivíduo não se sobreponha ao outro. Nos é claro que, em Levinas, é a partir do reconhecimento da subjetividade que se pode pensar o humano.

No tocante a transcendência, Sayão (2010, p. 313) nos explica que, para Levinas, "o conceito de transcendência desenvolvido na ideia do infinito, exterioridade absoluta expressa por um rosto, expõe a ética como sendo original e primeiro do que se convencionou chamar de humano", o que reforça o pensamento de Levinas quando este menciona que a ética é a primeira filosofia à constituição do humano.

Levinas busca, segundo Gallina (2008), redescobrir o humanismo a partir da humanização do próprio homem, que seria um processo onde não são estabelecidas metas nem ordens a serem cumpridas, mas sim uma humanização baseada na ideia de preocupação com o Outro, de se colocar no lugar do Outro.

Ainda nesse sentido, Agripino (2014, p. 17) nos apresenta que os problemas do humanismo estão ligados a ideia de fundamentos da ética, que Levinas considera como primeira filosofia, e que tais fundamentos devem ser reavaliados sobre um prisma que "retire o EU da centralidade, e se volte para uma abertura e acolhimento do Outro". Assim, estaríamos no trajeto de um humanismo contra hegemônico, marcado pelas alteridades.

Neste contexto, ela ainda nos explica que um dos obstáculos enfrentados pela humanização consiste no fato de que a sociedade ocidental está presa ao egoísmo, onde sempre se coloca as necessidades e problemas pessoais frente às dificuldades do sujeito que nos cerca, como já mencionado.

Em um cenário amplo, é possível observar que Levinas considera, em seus textos, um humano que vai além de definições, um humano consciente, preocupado com o Outro, um humano que não se prende a definições, onde generosidade e acolhida são requisitos básicos para se pensar a humanização, uma humanização que mesmo com o passar dos anos, e com 
todos os estudos realizados até então, não foi possível ser alcançada a partir do imaginário e das relações estabelecidas a partir do modelo de ocidental.

\subsection{Alteridade e reconhecimento: concepções e confluências}

Busca-se neste subitem compreender as concepções acerca do humano trazidas por Levinas, a partir das noções de alteridade e reconhecimento. Para entender suas ideias sobre alteridade, trabalharemos com três concepções suas que giram em torno da ideia central do humano, quais sejam: o Outro, a Sombra e o Mesmo.

Para ele, o Outro é aquele que parte da ideia de alteridade, a Sombra seria aquele que somos intimamente, com nossos desejos, medos e angústias, e o Mesmo, aquele que aparentamos ser, a nossa suposta imagem.

Levinas ao tratar de conceitos do ser, acredita que tais noções impedem a alteridade que ele tanto defende, e que leituras que buscam explicá-lo se tornam sempre repetitivas e exaustivas, uma vez que sempre retornam ao Mesmo.

Pelizzoli (2009, p. 261), nos diz que "se queremos a alteridade, precisamos abraça-la inteira". A ideia de alteridade trazida por Levinas é uma concepção onde nós devemos nos colocar no lugar do Outro, e nos preocuparmos com o ele, ficando felizes com suas conquistas, só assim pensa-se chegar, aproximadamente, do que seria o humano.

Essa alteridade, de que trata Levinas, é o que pode nos levar a respeitar e aceitar a diversidade humana, rompendo com as dicotomias e categorizações do humano, bem como com binarismos que são reforçados pela sociedade ocidental, que, através de seus discursos, impedem a existência do Outro.

Santos (2004) nos mostra que Levinas, baseado na infinitude da subjetividade, divide o ser humano em duas partes, o Mesmo e o Outro, e de que, mesmo que estes tenham alguma afinidade, ainda assim, se mantêm separados, e que só a partir dessa ideia de separação é possível compreender o sentido do humano a que se propõe Levinas.

Sobre a alteridade, Santos nos mostra que:

Levinas insiste sobre o fato de não haver um terceiro termo que englobe ou abarque a relação entre o Mesmo e o Outro, porque, neste caso, a distância entre os termos seria anulada; além disso, só há Outro em relação ao Mesmo, ou seja, é preciso que o Mesmo permaneça como "ponto de partida", como 'entrada', na relação, para que a alteridade do Outro seja possível (2004, p. 33, grifos do autor). 
Isso nos mostra que, para que o Outro exista é preciso que o Mesmo seja o fundamento parte central do humano, a manutenção deste. Por outro lado, Levinas expõe que não será o Mesmo nem o sujeito o ponto de partida ou o fundamento da filosofia, mas sim a ética.

Para Agripino (2014), o Eu é consequência da ligação com o Outro, mantendo a separação entre eles, sem retornar ao Mesmo. São discussões que não se prendem a uma totalidade, e que não voltam ao seu início, o Mesmo, mas que busca a transcendência do humano.

Ela ainda nos explica que o Eu, mesmo possuindo uma identidade, está em constante mudança, entretanto, sempre é o Mesmo, e que mesmo que busque outras significações, outros aspectos, sempre estará fadado ao retorno de si Mesmo.

Cabe aqui nos questionarmos quem é o Outro a quem Levinas se refere. Agripino nos mostra que:

\begin{abstract}
Lévinas traz da tradição judaica os modelos que concretizam seus argumentos sobre o Outro, destacando-os como categorias da alteridade: o pobre, o estrangeiro, o órfão e a viúva, que são indefesos, os marginalizados, os diferentes que clamam por justiça. Apenas a consciência moral pode reconhecer esse Outro [...]. Assim o Outro, palavra profunda e misteriosa, não se esgota no Mesmo (2014, p. 32).
\end{abstract}

Assim, é possível observar que o Outro, de que trata Levinas, é o Outro marginalizado pelo pensamento ocidental, que categoriza, padroniza e seleciona os indivíduos que nela se encontram. Essa resistência em se colocar no lugar do Outro, em trabalhar a ideia de alteridade, pode estar ligada ao fato de não aceitar a condição de diferente do sujeito, de querer que o Outro seja sempre igual ao Mesmo.

Em seu livro "Da Existência ao Existente", que começou a ser escrito quando ele ainda estava no cativeiro, durante a Segunda Guerra Mundial, como nos diz Mancer (1994), Levinas pôde observar como a alteridade é negada em detrimento do que alguns acreditam ser o melhor, que era a busca por uma raça pura, ou seja, de como "o outro era negado em sua alteridade e afirmado em sua diferença a partir do sentido que recebiam em função do projeto alemão" (MANCE, 1994, p. 24).

Mance, ainda nos diz que,

[...] na relação de proximidade entre o eu e o outro, estabelece-se a curvatura do espaço intersubjetivo, ou a assimetria: o outro situa-se num plano mais elevado que o eu. Pela sua palavra o outro é mestre do Mesmo e o ensina, devendo o eu julgar sua vida a partir da palavra do outro, com a consciência de que jamais se é justo o bastante (1994, p. 24, grifo do autor). 
Assim, quer nos mostrar que o Outro se sobrepõe ao Mesmo, assim como Levinas tenta nos esclarecer que o Outro deve servir de parâmetro para que possamos analisar nossas ações, mesmo sabendo que nunca seremos suficientemente justos em nossos julgamentos.

Ainda no tocante a ideia de Outro, Miranda (2011, p. 174) diz que além de todas as definições trazidas por Levinas sobre o ser, o rosto pode nos trazer um novo significado a respeito do Outro, quando fala que: "Portanto, o rosto entendido como significância ética, surge como o elemento novo capaz de produzir um traumatismo no eu e inscrever no seio da sensibilidade - gozo e fruição - o acolhimento e a responsabilidade ao outro como sentido ético da subjetividade".

Assim, o rosto seria uma personificação do Outro, a sua materialidade, e que deve ser enxergado pelo Mesmo. O rosto abre a possibilidade de se pensar na alteridade de maneira prática, uma vez que passa a ser matéria, passa a ser concreto, e não mais se coloca apenas no plano da subjetividade.

Miranda (2011, p. 176) menciona que é justamente nesse encontro do Eu com o Outro que Levinas propõe para que seja possível a alteridade, e que, é a partir desse encontro, dessa relação de proximidade, que vai ser possível pensar o Outro, pensar "a possibilidade de se pensar uma nova ética com o Outro".

Quando nos deparamos com a Sombra a que se refere Levinas, Pelizzoli (2009, p. 261) nos mostra que "o lado positivo da Sombra é ligado imediatamente à arte, dons sufocados, criatividade estética, que para muitos facilmente coaduna com um afrouxamento da moral", ou seja, a Sombra, nem sempre, quer revelar uma possível parte má que possa existir no ser, muitas vezes é uma parte do ser que ele mantém oculta, com medo de uma possível rejeição por parte da sociedade ocidental.

Ainda sobre as ideias a respeito do ser, que são características do pensamento de Levinas, Pelizzoli (2009, p. 264) nos fala que "um dos bons ensinamentos aqui da trilogia AlteridadeSombra-Emoções, seria tomar consciência de que eu, professor, acadêmico ou cientista, sou muitas vezes débil, como marionete, contaminado pela matrix".

A noção de "matrix" a que ele se refere pode estar ligada a sociedade ocidental, que busca, a todo instante, moldar o ser humano de acordo com suas exigências, e como a sociedade é composta por seres humanos, e estes são suscetíveis a mudanças, estas exigências são sempre reformuladas. 
Costa e Caetano (2014, p 199) nos dizem que a sociedade ocidental se conduziu a uma totalidade onde sua população busca, de forma demasiada, o poder e a dominação, conquistada através das inovações tecnológicas e científicas, e que tem, por consequência, seres humanos presos em si mesmos, "preso ao seu desejo de poder e de produção de consumo".

Sobre a ideia de alteridade eles ainda nos falam que:

\begin{abstract}
A dimensão da Alteridade pensada por Lévinas, provoca uma mudança interior, aspirando uma sociedade melhor para se viver. Calcado na subjetividade acolhedora do Rosto, o direito não se reduzirá a uma racionalidade procedimental que dita códigos, normas, responsabilidade, mas se tornará promovedor da paz e do bem para todos (COSTA; CAETANO, 2014, p. 205).
\end{abstract}

Isso nos mostra que Levinas busca, através da alteridade, uma sociedade mais humanizada, voltada para o bem do Outro, uma sociedade solidária, onde é preciso que se veja além de seus próprios interesses e do Mesmo, para que se alcance a paz.

Bernardes (2012, p. 94) nos fala sobre a ideia de totalitarismo, nos explicando que,

\begin{abstract}
A ruptura com a noção de totalidade, isto é, a concepção de sistemas que abarquem o todo e que não é, em si, a novidade no pensamento levinassiano, tem implicações de caráter ético-político, pois se atrela às críticas aos totalitarismos, às revoluções utópicas que pretendem transformar a sociedade como um todo e mesmo às ciências, quando estas se apregoam a capacidade de um saber total.
\end{abstract}

Aqui ele nos mostra que a ideia de totalitarismo é perigosa, uma vez que ela tende a unificar as sociedades, e, consequentemente, seus indivíduos, e que seu caráter político muitas vezes está apenas interessado em padronizar o humano e sua subjetividade.

Diante disso, é plausível pensar que a concepção de Outro de que trata Levinas está pautada na ideia de alteridade, que somente será possível quando o Mesmo se colocar no lugar do Outro, através da exterioridade, sem se preocupar se vai haver uma reciprocidade, mas apenas e tão somente preocupado com o Outro, porque esta é uma relação (Mesmo com o Outro), que deve ser desinteressada, onde o Mesmo deve ser responsável pelo Outro, sem pensar em uma possível recompensa, mas a partir de uma relação horizontal.

\title{
2.3 Por uma noção de subjetividade: sobre a configuração do Outro em Levinas
}

Sobre a (r)existência do Outro na sociedade ocidental, a qual Levinas atribui a ideia de alteridade, vejamos: "Nossa sociedade e nossa história se explicariam assim por essa resistência 
em aceitar o Outro, por essa violência instituída estampada nas pequenas e grandes histórias onde se nega ao outro a palavra e a possibilidade para que este seja" (SAYÃO, 2010, p. 311).

Essa resistência em aceitar o Outro possivelmente está ligada a não aceitação da diferença e diversidade humana, de querer que todos sejam iguais e sigam um padrão aceito pela sociedade ocidental, para que assim sejam acolhidos, fortalecendo dicotomias, ou seja, a partir da negação das subjetividades.

Segundo Cruz (2013), por vivermos em uma sociedade capitalista, onde a desigualdade é cada vez maior, e questões socioculturais são opressoras, sejam elas relacionadas a gênero, sexualidade, religião ou etnia, a lógica das relações humanas é precedida pela subalternização das subjetividades. Assim, as condições de diferença (ser mulher, homossexual, negro, indígena, crianças e etc.), se tornam um elemento de diferenciação, no sentido negativo da palavra.

Podemos observar que tais manifestações buscam, na verdade, respeitar o indivíduo, exatamente por sua diversidade, por sua condição de ser diferente (não atender as expectativas da sociedade - e pensamento ocidental - que busca padronizá-lo). Manifestações através de movimentos feministas, de manifestos que reivindicam que os direitos de homossexuais sejam reconhecidos, e de movimentos da população negra, que historicamente, são grupos que sempre foram oprimidos, seja através da escravidão ou do racismo, e que na nova feição das relações humanas, buscam afirmar suas subjetividades na diversidade.

Ao propor o reconhecimento do Outro, Levinas dialoga com a ideia de alteridade, cogitando que através dela é possível imaginar que o humano exista de forma plena, que é possível que esse Outro exista em uma sociedade ocidental na qual sua condição de diferente não seja negada.

Pinheiro (2011), diz que o preconceito surge através de conceitos de intolerância, socializados por determinada pessoa, por meio de concepções que o sujeito tem, acreditando que estas são verdades absolutas. Articula, ainda, que tais conceitos são advindos da cultura e do espaço ao qual o sujeito está inserido, racionalizando-o a partir de uma matriz imagética hegemônica.

Observando este entendimento de Pinheiro (2011), poderíamos chegar à conclusão que o preconceito é formado dentro do espaço que o sujeito ocupa, e que é reforçado com o passar dos anos, sem que ele sequer chegue a pensar neste posicionamento, não fazendo reflexão alguma sobre ele, e apenas perpetuando a negação da existência e da diversidade humana. 
O preconceito, ainda nas palavras da autora, é algo que é inerente à força cultural do sujeito, que não passa a refletir sobre a realidade, seja por medo de não reconhecer, de fato, a diversidade do Outro, preceito este que deve ser respeitado para reconhecer que a cultura do Outro "aponta para a universalidade humana".

Diz ainda, que as desigualdades existentes entre os grupos sociais, não deveriam separálos ou segregá-los na sociedade, e que, quando isso ocorre, existe pela não aceitação da diferença e diversidade do Outro, fazendo com que o pensamento ocidental, aquele que se considera como modelo e padrão, acredite ser superior aos demais grupos sociais existentes.

Cruz (2013), nos leva a pensar que, por mais que os movimentos das ditas "minorias" (pessoas negras, mulheres, homossexuais, índios, idosos, jovens, pessoas deficientes, etc.), sejam levados em consideração e tenham suas reclamações ouvidas por parte do Estado, é necessário não se deixar levar por um sentimento de dever cumprido, pois é preciso refletir até que ponto se quer chegar com tais reivindicações, pois o fato de haver ter algum avanço, não dá a estes grupos uma paridade de direitos em relação a sociedade que se considera hegemônica em relação a esses sujeitos.

Sobre o modelo de sociedade ocidental que é apresentado aos seres humanos, Sayão nos fala que:

\footnotetext{
Absorvemos a atmosfera de sentidos que nos cerca e por ela somos bombardeados por valores e leituras de realidade que nos falam das mais e menos valia das pessoas em razão do ter, do acumulo de bens e do poder que essas assumem diante do mundo; somos ensinados a valorizar o consumo, a competição, a força, a guerra; somos adequados a um jogo de significação na qual uns são e outros não, no qual temos que nos esforçar para ser e nos preservar, e é esse caminho que precisa ser revisto (2012b, p. 245).
}

É possível observar que, diante de palavras como "uns são e outros não", "temos que nos esforçar para ser e nos preservar", vemos, de maneira clara, que o pensamento ocidental busca padronizar o sujeito e capturar sua subjetividade, impedindo que ele viva em sua plenitude, livre de modelos que são estabelecidos.

Assim, o fato de não pararmos para enxergar o Outro, de não pararmos para deixar que ele viva à sua maneira, nos torna seres humanos incapazes de compreender qualquer sentimento, principalmente de tentar entender o que de fato é o ser humano.

Isso ocorre, muitas vezes, porque somos egocêntricos, e queremos que os padrões que são estabelecidos por nossa sociedade ocidental sejam correspondidos, e, assim, impedimos que o Outro exista em sua completude, impedindo-o de vivenciar sua verdadeira identidade. 
Para Barroco (2006), a negação da existência e condição de diversidade do Outro, através de intolerância e do desrespeito, é uma atitude perigosa, pois, uma vez que não se dá espaço à diversidade, abre-se espaço para nossos preconceitos, racismos e intolerâncias, tomando aquilo que acreditamos como verdade, uma imposição para que ela se torne a verdade também do Outro.

Analisando a tolerância, no sentido de respeito à diferença, e a intolerância como um desprestígio ao Outro, Barroco (2006), nos diz que a tolerância tem seu valor positivo a partir do momento que pode criar uma ligação social entre essas pessoas, enquanto que a intolerância torna essa ligação, e, por conseguinte, a existência de respeito, praticamente nulas.

Ainda no que diz respeito as expectativas da sociedade ocidental, Sayão nos mostra que:

Levinas sabe que a face do ser que se mostra na guerra, fixa-se no conceito de totalidade que domina nosso modo de ser ocidental. Fato que se coloca como um vórtex onde tudo e todos são enquadrados em determinações prévias, que lhes definem seu destino e dentro do qual os próprios indivíduos vão buscar o sentido para si e para a diversidade do mundo como um todo (2012b, p. 252).

Quando se fala em "determinações prévias", estamos nos referindo ao modelo do pensamento ocidental que busca em seus indivíduos, estamos falando dos padrões e mecanismos de captura da subjetividade e da diferença que são criados, e de como estes marcos perturbam a formação do sujeito.

As relações entre os indivíduos da sociedade, entre o Mesmo e o Outro, se tornam, desta maneira, complicadas, porque uma vez que não atendem ao modelo desejado, o Outro passa a ser marginalizado, passa a não ser reconhecido.

O Outro que Levinas nos fala é um ser que precisa ser reconhecido, mas que seu reconhecimento é negado pela sociedade ocidental, e, assim, Sayão nos mostra que

[...] Levinas chega ao modus operandi ocidental, que em sua base é violento e aviltante porque nega a diferença e é alheio à diversidade. Nele, o pensamento vai às coisas e as determina sem sair do lugar, num jogo de forças da identidade em que esta não é afetada, e nisso toda moral está suspensa e todas as leis são convertidas nas leis de quem tem a palavra (2012b, p. 253, grifo do autor).

Ou seja, mais uma vez depara-se com a discussão de que o pensamento ocidental molda os seres e impede que o Outro exista e seja reconhecido, porque ele não corresponde aos modelos que lhe são dados e exigidos.

Sayão (2012b, p. 292) nos mostra que quando não damos chance à alteridade, que é um problema que Levinas identifica na filosofia de sociedade ocidental, isso acarreta em um grande 
inconveniente, porque ficamos presos "à uma determinada necessidade de controlar o mundo e a realidade, assim como nós mesmos".

Levinas acredita, como já citamos, em um ser humano pleno, e, ousamos em dizer, quase divino, marcado pela leveza do humano. Uma imagem que foge a toda e qualquer explicação, e traz o respeito em seu livro, citando que: "O termo respeito pode ser retomado aqui; desde que se sublinhe que a reciprocidade deste respeito não é uma relação indiferente, como uma contemplação serena, e que ela não é o resultado, mas a condição da ética. Ela é linguagem, ou seja, responsabilidade" (LEVINAS, 1997, p. 61).

É necessário que o respeito seja um caminho que aproxime os sujeitos, e não uma maneira padronizada, ou subterfúgio de fazer com que o Outro possa coexistir dentro do mesmo grupo social, descaracterizado em sua subjetividade, mas que mesmo assim esteja à margem das relações sociais.

Assim, o reconhecimento do Outro, através da alteridade, proposta por Levinas, pode ajudar a sociedade ocidental a pensar uma sociedade mais humana, uma sociedade mais ética, onde serão observadas as subjetividades, sem que, em contrapartida, seja preciso que este Outro precise se adequar a nenhum padrão.

\section{CONSIDERAÇÕES FINAIS}

Esta pesquisa buscou relacionar o pensamento levinasiano buscando uma saída para, através dessas ideias, repensar o problema ocidental dos direitos humanos, a noção de sujeito que está ligada ao imaginário ocidental, apontando possíveis pistas sobre a ideia de subjetividade nestes marcos, a partir da qual Levinas nos apresentaria uma nova percepção de sujeito enquanto elementos diverso e plural das relações pessoais.

Com esta pesquisa é possível afirmar que os padrões que são disseminados em nossa sociedade, e que estão enraizados no pensamento dos sujeitos que compõem a mesma, impedem o sujeito de existir de maneira plena e impossibilitam as diversas formas de identidades e manifestações das diferenças (subjetividades).

Assim, nossa pesquisa leva-nos a considerar o ser humano como sujeito que deveria nascer livre e pleno em sua condição humana. Entretanto, o pensamento ocidental é levado, através de discursos de poder, a categorizar os indivíduos desde o momento de sua concepção. 
Também foi possível observar que Levinas (1997) busca, a todo instante, um fundamento que nos leve a pensar no humano fora de todas as ideias que nos são apresentadas. A nós, esta ideia pode ser alcançada a partir da reflexão de subjetividade implicitamente presente em seus escritos.

Entender o sujeito dentro das relações sociais, e dentro do pensamento ocidental, avaliando ainda todo um campo que lhe é exterior, é matéria que nos causa grande inquietação, pois devemos nos despir de todos os conceitos que nos foram "empurrados" até os dias de hoje. É necessário adentar em um mundo de completa desconstrução, para que seja possível construir, ainda que de maneira equivocada, uma noção que se aproxime da ideia de sujeito.

É preciso garantir, de maneira eficaz e incisiva, que estas desigualdades não se sejam banalizadas pelo simples fato de "aceita-las". É necessário que se reconheça o sujeito enquanto ser humano, que além de ter os mesmos direitos que os demais, precisam que eles sejam legitimados.

Pensar no sujeito enquanto elemento fonte e guia das relações sociais, enquanto "matéria-prima", buscar um novo caminho para se pensar em/nos direitos humanos, colocar a dignidade da pessoa humana como fundamento da norma.

Se faz primordial reconhecer o sujeito enquanto pessoa, desvelado de todos os conceitos, padrões, todas as ideias e parâmetros que foram utilizados até hoje para tentar conceituar um sujeito que já nasce com uma "cicatriz" do que deve ser e de como deve se ajustar em meio a sociedade.

Desse modo, é fundamental imaginarmos um sujeito puro, conexo a sua dimensão mais subjetiva, para que assim seja possível pensar em fundamentar direitos humanos para humanos. E não é buscando padrões ou normas que regulem a maneira de como esse sujeito deve ser e se comportar, que estaremos construindo uma sociedade pautada na liberdade, respeito e igualdade.

Assim, e só assim, será possível fundamentar Direitos Humanos. A partir do momento que a sociedade ocidental passe a observar o sujeito enquanto pessoa, enquanto diferente, pois não somos iguais, e passar garantir e reconhecer que o Outro também é detentor de direitos.

Quando a ideia de sujeito não mais estiver ligada a padrões, quando o indivíduo não precise se moldar as normas e possa exercer sua condição de diferente, quando puder viver sua identidade sem se orientar por discursos é que, certamente, alcançar-se-á o sentido do Outro 
proposto por Levinas. Só quando a sociedade parar para racionalizar o Outro é que será possível garantir as expressões mais subjetivas que perfazem o humano.

\section{REFERÊNCIAS}

AGRIPINO, V. I. (2014). Humanismo como ética: um estudo sobre a alteridade em Emmanuel Levinas. Dissertação de Mestrado. Universidade Federal da Paraíba- UFPB, João Pessoa, Brasil.

BARROCO, M. L. S. (2006) Ética, direitos humanos e diversidade. Cadernos Especiais, 1 (37), 1429.

BERNARDES, C. T. T. (2012) A ética da alteridade. Revista de Cultura Teológica. 20 (78), 83-101.

BONAMIGO, G. P. (2016). O problema do humano em Emmanuel Lévinas. O que nos faz pensar. 25(38), 139-160

CARRARA, O. V. (2008). Levinas: do sujeito ético ao sujeito político. Tese de Doutorado. Universidade do Estado do Rio de Janeiro, Brasil.

COSTA, J. X. S.; CAETANO, R. F. (2014). A concepção de alteridade em Levinas: caminhos para uma formação mais humana no mundo contemporâneo. Revista Eletrônica Igarapé, 1 (3), 195210.

CRUZ, D. E. S. (2013). Diversidade humana e a crítica à igualdade de oportunidades e às formas de particularismo na sociedade capitalista. VI Jornada Internacional de Políticas Públicas, 1-8.

GALLINA, R. (2008). Ontologia da alteridade: "humanos, outramente humanos". Dissertação de Mestrado. Universidade de Brasília-UBN, Brasil.

LAPA, R. S. (2017). A alteridade como fundamento para uma teoria crítica de direitos humanos. Dissertação de Mestrado. Universidade de Brasília, Brasil.

LEVINAS, E. (1997). Entre nós: ensaios sobre a alteridade. Petrópolis: Editora Vozes.

MANCE, E. A. (1994) Emmanuel Levinas e a Alteridade. Revista Filosofia. 8 (7), 23-30.

MELO, N. V. (2003). A ética da alteridade em Emmanuel Levinas. Porto Alegre: Edipucrs.

MIRANDA, J. V. A. (2011). Sensibilidade ética em Emmanuel Levinas. Kinesis. 3 (6), 170-183.

PELIZZOLI, M. (2009). A inclusão da sombra e da alteridade: é possível a ética? In: PELIZZOLI, M. Cultura de Paz: a altetidade em jogo. (Cap. 11, pp. 251-267) Recife: Universitária da UFPE.

PINHEIRO, V. P. G. (2011). Preconceito, moralidade e educação moral para a diversidade. Revista Brasileira de Educação. 16 (46), 215-233. 
SANTOS, M. L. L. Q. (2004). Subjetividade como responsabilidade em Levinas: quando a alteridade atravessa o sujeito. Dissertação de Mestrado. Universidade Federal de Pernambuco-UFPE, Brasil.

SAYÃO, S. C. (2009). Ética, responsabilidade e reconfiguração da subjetividade em Emmanuel Levinas: o argumento da paz. In: PELIZZOLI, M. Cultura de Paz: a alteridade em jogo. (Cap. 10, pp.233-250) Recife: Universitária da UFPE.

SAYÃO, S. C. (2010). A ideia do infinito e da ética em Emmanuel Levinas como fundamento para pensar os direitos humanos e a paz. In: PELIZZOLI, M. Cultura de Paz: restauração e direitos. (Cap. 13, pp. 301-322). Recife: Universitária da UFPE.

SAYÃO, S. C. (2012b). Indiferença, Insensibilidade e Diálogo: Reflexões sobre o encontro humano. In: PELIZZOLI, M.; SAYÃO, S. Dialógo, Mediação e Justiça Restaurativa: cultura de paz. (Cap. 11, pp. 243-264) Recife: Universitária da UFPE.

SAYÃO, S. C.(2012a). Sensibilidade e infinito: Emmanuel Levinas e o argumento da paz. In: SAYÃO, S.; PELIZZOLI, M. Fragmentos Filosóficos: direitos humanos e cultura de paz. (Cap. 12, pp. 235-266). Recife: Universitária da UFPE.

SIDEKUM, A. (2005). Liturgia da alteridade en Emmanuel Levinas. Utopia y Praxis Latinoamericana. 10 (31), 115-123. 